\title{
Factors facilitating patient satisfaction among women with medically unexplained long-term fatigue: a relational perspective
}

Olaug S Lian ${ }^{1}$ and Anne Helen Hansen ${ }^{1,2}$

Last version before proofreading and print, final version available at http://journals.sagepub.com/doi/abs/10.1177/1363459315583158

Please quote as: Lian, O. S., \& Hansen, A. H. (2016). Factors facilitating patient satisfaction among women with medically unexplained long-term fatigue: A relational perspective. Health:, 20(3), 308-326.

${ }^{1}$ Department of Community Medicine, University of Troms $\varnothing$ - The Arctic University of Norway, Norway

${ }^{2}$ Norwegian Centre for Integrated Care and Telemedicine, University Hospital of North Norway, PO Box 35, 9038 Troms $\varnothing$, Norway

\section{Corresponding author}

Olaug S. Lian, Department of Community Medicine, Faculty of Health Sciences, University of Troms $\emptyset$ - The Arctic University of Norway, N-9037 Troms $\emptyset$, Norway. Email:

olaug.lian@uit.no

\section{Funding}

The author(s) disclosed receipt of the following financial support for the research, authorship, and or publication of this article: The Norwegian Research Council, Research Program of Health and Care Sciences (grant no. 212978). 


\begin{abstract}
Bodily conditions that are difficult to identify, explain and treat with the aid of medical knowledge and technology appear to be particularly challenging to medical encounters. Patients are often dissatisfied with the help they receive, and they often experience that their medical needs are not met. To explore factors facilitating patient satisfaction among patients with a medically unexplained condition we ask: what is the importance of individual versus relational factors in facilitating patient satisfaction in clinical encounters between general practitioners (GPs) and women with medically unexplained long-term fatigue? We approach this question through a statistical analysis of survey data collected from a net sample of 431 women recruited through a patient organisation for people suffering from myalgic encephalomyelitis (ME) in 2013. Participants were asked about their experiences with general practitioners in the Norwegian national health system in two different phases: shortly after illness onset, and current regular GP last 12 months. The questions evolved around themes concerning shared understanding and decision-making, being taken seriously, being paid due respect, and being treated as an equal partner. Through descriptive statistics and multivariable logistic regression analyses, we explored how their experiences were related to individual and relational factors, respectively. Free-text comments from the questionnaires were used while interpreting the results. The analysis illuminates that relational aspects in medical encounters between GPs and ME-patients, especially continuity, congruence in doctor-patient views and being seen by a specialist, are important catalysts of patient satisfaction. The probability of being satisfied with the initial investigation was more than six times higher in women who were referred to specialists, compared to those who were not. We conclude that continuity of care and experiences of being in a partnership that operates on a common ground - a shared understanding of the patient's illness - foster patient satisfaction among women with medically unexplained long-term fatigue.
\end{abstract}




\section{Introduction}

During the last decades, cultural changes have transformed the role of the doctor, the role of the patient, and the relation between them; assumingly to a less authoritative role of the doctor vis-à-vis the patient (Sacristán, 2013). Delivering evidence-based medical services of high quality, consistent with the patient's medical needs and in a way that fosters doctorpatient partnership and shared decision-making, are qualities strived for in all Western health care systems (Hibbard \& Greene, 2013). These objectives are promoted through health policy initiatives, but the decisive factor for success is found at the end of the line, in the meeting between patient and doctor. To understand what supports and hinders the realisation of these highly sought-after values we therefore need to study the micro-level of health care services, and preferably its core element: the medical encounter.

In medical encounters between doctors and patients presenting medically unexplained symptoms, which is estimated to be about one in five patients seen in primary care settings (olde Hartman, 2011), patient-doctor partnerships seem to be particularly difficult to achieve. For doctors, their credibility as competent partners is at stake (Horton-Salway, 2002). For patients, it is important to receive acceptance for having an actually existing disease (Nettleton, 2006). While describing such relationships, 'battlefield', 'minefield' and other warfare metaphors are used (Werner et al., 2004; Thompson et al., 2009). If left unresolved, the situation might have a detrimental effect on patient's coping skills (Edwards et al., 2007) and - in the end - the clinical outcome of consultations (Stone, 2014).

Medically unexplained long-term fatigue is a condition that seems to be particularly challenging, for both parties (Anderson et al., 2012; Stone, 2014). The most recent diagnosis for this condition - myalgic encephalomyelitis (ME) - is currently classified as a neuroimmunological condition in ICD-10 (WHO 2010, code G93.3). The key symptom is a postexertional fatigue which does not disappear after resting, accompanied by wide range of 
functional impairments, such as malaise, dys-regulation of body temperature, bowel problems, sleep disturbances and cognitive problems (Carruthers et al., 2011; NICE, 2014). Some become bed- or housebound for years. ME-patients often need long-term coordinated care from different providers, and GPs are usually their main partners. The worldwide estimated prevalence varies between 1 percent and 1-2 per thousand (Fluge et al., 2011), and those who receive this diagnosis are predominantly women (ratio estimated to be $6: 1$ ) (Capelli et al., 2010). The typical patient is often stereotyped as a well-educated perfectionist woman (Hart \& Grace, 2000). These female connotations might contribute to the ways in which the two parties interact, and how they interpret this interaction.

ME is a typical medically unexplained condition. First of all, its aetiology is uncertain and heavily debated. Some describe ME as an autoimmune disease (Fluge et al., 2011); others as somatisation of stress (Wyller et al., 2009). Secondly, the symptoms are unaccounted for with observable biomarkers to verify organic disease. Thirdly, there is no known efficient medical treatment, and doctors' main therapeutic tool is communication. Because the condition is difficult to identify, explain and treat with the aid of medical knowledge and technology, these encounters represent a serious challenge to doctor-patient collaborations (Stone, 2014; Anderson et al., 2012; Banks \& Prior, 2001).

In this paper, we explore the experienced quality of health care services among women suffering from medically unexplained long-term fatigue. Our discussion is based on a statistical analysis of data collected through a questionnaire distributed to members of The Norwegian ME Association. We limit our study to 431 women and their experiences of the quality of consultations with general practitioners (GPs) within the Norwegian National Health System $^{1}$, related to three main themes: 1) sense of partnership and shared decisionmaking, 2) experience of being taken seriously and being paid due respect, and 3) congruence in the ways in which doctor and patient understand their illness. Our main aim is to identify 
factors that are associated with positive and negative patient experiences. Individual factors like age, education and health status are known to be important and persistent predictors of patient satisfaction (Hall \& Dornan, 1990), but the question is: are these factors equally important for patients with medically unexplained conditions? Through statistical analyses of the survey data, we explore the importance of individual versus relational factors in facilitating patient satisfaction in clinical encounters between patients with medically unexplained long-term fatigue and their GPs.

\section{Patient satisfaction: theory and previous research}

Patient satisfaction, understood as "an individual's cognitive evaluation of, and emotional reaction to, his or her health-care experience" (Shirley \& Sanders, 2013: 1), measures the extent to which patients perceive their needs to be met (Serber et al., 2003). Such experiences have been widely studied in Western societies during the last decades, but we still lack knowledge about the interplay of underlying mechanisms that foster patient satisfaction in various clinical settings.

The quality medical encounters, as patients perceive it, is influenced by both patients and doctors, individually, and by relational factors that cannot be exclusively tied to one of them. A common assumption in these studies has been that individual explanatory factors are important, either related to the doctor (such as age, gender, speciality and emphatic abilities), or to the patient (such as age, gender, socio-economic position (SEP), sense of coherence, mental state, disease specific knowledge, and health status). Empirical studies support these assumptions: women, older patients, patients with perceived better health status, and patients with lower education tend to be more satisfied (Rahmqvist \& Bara, 2010; Jackson et al., 2001; Hall \& Dornan, 1990). Among relational factors we find communication style (Willems et al., 2005; Hall et al., 2014; Weisman \& Teitelbaum, 1985), continuity of care 
(Schieber et al., 2013; Salmon et al., 2005; Whear et al., 2013; Beach et al., 2013; Hall \& Roter, 2002), experiences of partnership and shared decision-making (Street Jr et al., 2005; Ommen et al., 2011), congruence in doctor-patient beliefs (Serber et al., 2003; Krupat et al., 2001), and reciprocated trust (Croker et al., 2013). Greater satisfaction generally occurs

"when the patient has the perception of being listened to, of being treated with respect, humanely and as fairly as others" (Sans-Corrales et al., 2006: 309). Satisfaction involves a kind of (often mutual) trust, and doctors who are caring, comforting and competent and exhibit good communication skills foster patient trust - and thereby patient satisfaction (Thom, 2001). Factors facilitating patient satisfaction probably intersect with each other in a complex web of both individual and relational aspects within the medical encounter, and the relative importance of the different factors are likely to vary in relation to the type of ailment patients have.

\section{Patient satisfaction among patients with medically unexplained symptoms}

Previous research on the experiences of patients presenting medically unexplained conditions has revealed that patients often feel stigmatised, psychologized and disbelieved by their doctors: "Accounts of being met with scepticism and lack of comprehension, feeling rejected, ignored, and being belittled, blamed for their condition and assigned psychological explanation models are common" (Werner \& Malterud, 2003: 1409). In another study, olde Hartman and colleagues (olde Hartman et al., 2013) found that the patients' reasons for seeking help rarely were explored by the doctors, that patients got ample opportunity to tell their story, and that doctors rarely incorporated the patients' beliefs and concerns in their communication: "extensive explanations of the origin of the symptoms often did not take patients' beliefs and concerns into account" (olde Hartman et al., 2013: 354).

Epstein and colleagues (Epstein et al., 2006) report similar findings in an experimental study based on audio-recordings of consultations between two groups of actors 
performing as standardised patients presenting chest-pain symptoms to 100 general practitioners. Both groups presented the same level of illness severity, but while one group presented classic symptoms of gastroesophageal reflux disease (GERD), the other group presented poorly characterised chest pain with fatigue and dizziness (medically unexplained symptoms). Of the 100 doctors, 89 saw patients from both groups. Multivariate analyses of these 89 consultations in relation to measures of patient-centred communication, the researchers found statistically significant differences between the two types of consultations. For "patients" not presenting classical symptoms the doctors "did not explore and validate the patient's reason for visit, and their ideas, expectations, feelings, and functioning as thoroughly as in the GERD role" (p. 272).

\section{Patient satisfaction among ME-patients}

According to previous research, which is mainly of a qualitative kind, people experiencing unexplained long-term fatigue often feel misinterpreted, psychologized, doubted and stigmatized by doctors who meet them with medical ignorance, scepticism and moralization (Aronowitz, 1998). According to a review of 34 qualitative studies, ME-patients often report that their doctors question their moral character, and throw into doubt the reality of their

symptoms (Anderson et al., 2012). Women, who seem to be particularly exposed (Åsbring \& Narvanen, 2002), report "being told over and over again that there was no disease, and 'it is only in your head' (Moss \& Dyck, 2002: 89).” Their perceived lack of social support and accusations of malingering negatively affect their coping skills (Edwards et al., 2007). In online discussions on the internet, ME-patients complain about doctors who incorrectly attribute $\mathrm{ME}$ as being triggered by psychological factors, and who do not accept $\mathrm{ME}$ as a distinct somatic disease (Lian and Nettleton, 2014). Several studies show that many doctors have negative perceptions of these patients, holding the belief that they often exaggerate the 
severity of their symptoms, and that they also are sceptical about ME as a clinical diagnosis and as a disease (Anderson et al., 2012).

\section{Study design}

This is a cross-sectional study based on quantitative data and methods. In order to collect the data detached from sites of care, it was collected from members of the Norwegian MEassociation. By doing so, they could describe their experiences without fearing negative consequences for their relation with their GPs.

\section{Data}

In April and May 2013 (first invitation 22 April, reminder 22 May), a total of 811 members of the Norwegian ME-association received a postal survey where we invited them to participate in a study about how ME-patients experience the quality of services they are offered from the national health care system in Norway. Invitations were sent via emails by Norwegian Social Science Data Service (NSD) Web Survey, who received email addresses directly from the patient association. Only members with known email addresses were included (about $40 \%$ of all members). Of those invited, 11,5\% were men. The data from the organisation did not include information about age or membership reason, so we asked the candidates to refrain from participating if they were below the age of 16 , or not suffering from ME themselves. We do not know how many non-respondents were non-eligible.

\section{Participants}

A total of 488 people (60\%) responded. Due to non-response from non-eligible receivers and return of emails from email addresses not in use, the actual response rate is assumed to be higher. In this study we exclude all men (53 respondents), all who did not give information about their gender ( 2 respondents) and women who did not give information about their age ( 2 respondents). That gives us a net sample of 431 female respondents. According to 
themselves, 354 were diagnosed with ME, 31 with CFS and 70 with post-viral fatigue syndrome (multiple answers possible).

\section{Variables}

Participants were asked about their personal experiences with their GPs, mainly formulated by beginning with "to what extent", and with four alternative answers ranging from "to a great extent" to "not at all". These experiences were classified under two main headings: experiences with GP(s) shortly after illness onset and experiences with current regular GP last year. The seven questions that constitute the basis for our analyses are described in Table 2 and 3. From these we constructed seven dependent dichotomous variables by merging the answers "to a large or some extent" and "to a little extent or not at all" (Table 2). Participants were given the opportunity to give free-text comments to an open-ended question ("Is it something that you want to tell us that you have not yet said?"), which we used while interpreting the results of the statistical analyses.

Based on previous research we defined age, education, health status, seeing a specialist, duration of current regular GP relation, number of GP visits, and common understanding of the ailment between doctor and patient as factors likely to influence patient's experiences. The independent variables were classified under the headings individual and relational variables (relational factors located between the two parties are closely entwined with individual ones, and therefore difficult to keep apart in real-life situations, but for analytical purposes we find it useful to separate them). Individual variables were age in years, education, and self-rated health. Six original education categories were merged into four due to low numbers in the lowest (no education: $\mathrm{n}=1)$ and highest $(\mathrm{PhD}$ : $n=3$ ) educational groups. Response options for self-rated health were reduced from five original categories (very bad - bad - fair - good - excellent) to four by merging "good" and "excellent", due to low numbers (excellent $-\mathrm{n}=5$ ). The relational variables were referrals to 
specialist, whether they agreed in the doctor's explanation of their illness, number of GP visits last year (given at least one visit), and duration of current regular GP-patient relationship.

\section{Analyses}

Data were analysed by means of descriptive statistics and logistic regressions. Correlations were tested with Spearman's correlation coefficients. We decided on seven multivariable logistic regression models, one for each of the described dependent variables (three related to the initial phase, and four related to consultations with current regular GP last 12 months). Because we assumed that the importance of different factors would differ between different stages of the illness (diagnostic processes, which often include being referred to specialists, are most important in the initial phase), regression analyses of these two groups of models were set up with different independent variables. The independent variables were introduced collectively into the models. We used $95 \%$ confidence intervals $(\mathrm{CI})$ throughout the study. All analyses were accomplished using Stata, version 13.1. In our interpretation, we drew on free-text comments given by the participants to an open-ended question.

\section{Ethics}

We received ethical approval for this study from the Norwegian Data Protection Official on the $17^{\text {th }}$ of October 2012 (id. 31784). This approval covers all aspects of the study, including the information pack whereby we informed the candidates that their participation was voluntary, and that they could withdraw from the study at any time without giving any reasons for it. In addition, we gave details about the main purpose of the study, how to protect their anonymity, how to store the data, and our plans for publishing the results. 


\section{Results}

The youngest woman in our sample was aged 16, the oldest aged 73 (median age $=47$ )

(Table 1). More than two of three respondents defined their health as poor or very poor

(Table 1), which is a higher proportion than the population average ( 9 percent for women in 2012, Statistics Norway, 2014a). Our sample has a higher proportion of people with university education than the Norwegian average (61 and 33 percent, respectively, Statistics Norway, 2014b). Median duration of ME symptoms at the time of participation was 12 years (mean 13.6 years). From illness onset to diagnosis given by a doctor, the median number of years was 4 (mean 7.0 years). Nearly two in three reported having a long-term relation with their current regular GP (e.g. three years or more). More than half of them reported seeing their GP five times or more last year (Table 1). Most participants had views on what had caused their illness, which were mainly an infection (72 percent), long-term stress (40 percent), a physical trauma (15 percent), a vaccine (14 percent), and/or a psychological trauma (13 percent) (multiple answers possible). Those who received an explanation of the cause of their illness by their GP(s) in the initial phase, if any, were given psychosomatic $(26,8 \%)$, psychological $(20,4 \%)$ or physical explanations $(18,7 \%)$. There were no significant correlations $(>0.5)$ between the independent variables. A total of 226 women (52\%) included free-text comments to elaborate their answers.

\section{Patient's experiences: an overview}

About half of the 431 women reported that during GP visits shortly after illness onset, the GP(s) to a little or no extent investigated their ailment in a satisfactory manner (54\%), and that the GP(s) to a little or no extent took their problems seriously (46\%) (Table 2). The most negative answers appeared for the last and most general question - satisfaction altogether where one in four answered "not at all" (Table 2). 
Their experiences with their current regular GP were less negative (Table 3): about one in ten respondents answered that their current regular GP(s) to a little or no extent took them and their problems seriously (10\%), paid them due respect (11\%), allowed them to have an impact on decisions made (8\%), and shared their understanding of ME (13\%) (Table 3).

\section{Patterns of patient satisfaction - initial phase}

We found that the probability of being satisfied with the initial investigation made by their GP(s) was more than six times higher in women who had been referred to specialist services, compared to those who were not (Table 4). The associations took the same direction for the dependent variables "taken seriously" and "satisfied in general" (OR 4.44 and 5.97, respectively). Patients were less likely to be satisfied with the initial investigation, taken seriously, and satisfied in general with less agreement with the doctor's explanation of the illness (Table 4).

\section{Patterns of patient satisfaction - current regular GP last 12 months}

In age adjusted multivariable logistic regression analyses of questions related to consultations with their current regular GP last 12 months, we found patient's experiences mainly to be associated with two factors: number of GP visits last year (OR 5.38, CI 1.36-21.32 for 10 visits or more, compared to those with 1-4 visits), and duration of the current regular GP relationship (Table 5). The associations took the same direction for the dependent variables "My GP takes my problems seriously", "My GP pays respect”, “My GP supports my views" and "My GP and I have a common understanding of my illness", although not statistically significant for all of them (Table 5). Assessments were likely to be more positive in women whose GP relationship had lasted for 3 years or more, compared to those with a shorter relationship (Table 5), and even more so by those who reported more than ten visits compared to those with 1-4 visits last year (Table 5). 


\section{Discussion}

The participants reported less negative experiences for the period of the last 12 months, compared to the initial phase. This may be due to their having time to find a "right" GP (perhaps sometimes by changing several times before being satisfied), and that the two parties have had time enough to get to know each other and "adapt" to each other. Some of the free-text comments support this interpretation: "Got lousy help from GP in the beginning. Had to change doctor", and "I was not taken seriously. Got a new GP who believed in me".

\section{Initial phase}

Logistic regression analyses revealed that the patient's experiences were significantly associated with being referred to a specialist and agreeing in the doctor's beliefs about the cause of their illness. All statistical significant findings in the initial phase were related to these two factors.

The importance of being referred to a specialist probably relates to the time-factor (shortly after illness onset), the diagnostic difficulties, and the severity of the condition. With a rare and debilitating illness as ME, it is understandable if people would prefer to have a specialist opinion on diagnosis. This is confirmed by previous research informed by adolescents and mothers of children with ME/CFS, who experienced a lack of knowledge about ME/CFS both in primary and secondary services (Beasant et al., 2014). The mothers experienced specialist ME/CFS services as useful because it "recognised and acknowledged their child's condition and opened channels of dialogue between health-care professionals and education providers" (p. 134), and adolescents experienced that receiving specialist medical care enabled them to achieve better symptom management. Previous research substantiate these perceptions: non-experts on chronic fatigue have been shown to be 7.7 times more likely than experts (specialised in treating these patient) to perceive the aetiology of this condition as unclear, less likely to explain it as an immunological condition, and less 
able or willing to diagnose it (Swoboda, 2008). These findings are supported by other studies, where GPs express a lack of confidence about deciding on the ME-diagnosis (Chew-Graham et al., 2010). In highly specialized health care systems, perceived needs to see doctors with specialised expertise (theoretical knowledge as well as clinical experience) seems to be common for people suffering from rare conditions (Budych et al. 2012).

Several free-text comments indicate that patients perceive a delayed diagnosis, which they relate to a delay in seeing a specialist, as having a long-term negative impact on their symptoms, and several of them report "going private" to be diagnosed. Even more commonly expressed is the view that GPs have limited knowledge about ME: "ME is a disease many GPs do not have knowledge about", and "they know very little and nothing". Lack of knowledge among GPs is one of the most frequently mentioned viewpoints in the free-text comments.

The need to see a specialist is understandable, but how the fulfilment of this need links to a higher degree of satisfaction on several different quality indicators related to GP consultations is not straightforward. Why does a meeting with specialists interfere with the ways in which the patients perceive the quality of their GPs? One explanation could be the symbolic value of this act: by referring the patient to a specialist, the GP demonstrates good intentions, and a determination to help the patient. As these are fundamental aspects in a trusting relation, referrals to specialist might foster patient's trust in the GPs.

The statistically significant association between patient's experiences and agreeing in the doctor's beliefs about the cause of their illness is supported by previous research indicating that congruence in doctor-patient beliefs (including experiences of partnership and shared decision-making) are important in facilitating patient satisfaction (Budych et al., 2012; Serber et al., 2003; Street Jr et al., 2005; Ommen et al., 2011; Krupat et al., 2001). This does 
not mean that diverging views necessarily leads to dis-satisfied patients, but that diverging views represent a challenge to the medical encounter.

The importance of a shared understanding between patient and doctor of what caused the illness touches on a very controversial debate about the aetiology of ME, a debate that has been going on ever since long-term exhaustion became defined as a medical condition in the second part of the $19^{\text {th }}$ Century (Lian and Bondevik, 2015). The main site of tension is whether the exhaustions is psychogenic (caused by the mind) or somatic (caused by the physical body), or a blend of both. This relates to ME being a medically contested chronic condition that is difficult to identify, explain and cure with the aid of modern biomedical knowledge and technology. When disease cannot be confirmed by technological tests, when the border between somatic and psychiatric disorders is in dispute, and/or when the problem is systemic and cannot be localised in a particular body part, the condition often become medically contested (Lian and Nettleton, 2014). This must be seen in relation to its cultural context, particularly our dualistic thinking of psyche and soma, and the epistemological foundation of our medical cosmology (what we can know for certain is what we can observe via technological techniques). The modern biomedical cosmology is a way of knowing based on scientific knowledge and medical technology. Technologically generated findings provided by laboratory procedures and by mechanical and electronic devices play an important role in the diagnostic process (Jewson, 2009). Within this cosmology, invisible and medically unexplained symptoms become "matter out of place". Those who experience the illness, and also interpret the ways in which it appears to them, have a different perspective on the phenomenon in question (the illness) than the medical one (an experiential perspective). These different perspectives are "at the root of the fundamental distortion of meaning in the physician-patient relationship (Toombs, 1992: xv). This complicates the collaboration between doctor and patient. In the case of ME, an additional challenge is that 
doctors and patients often disagree on the nature of their ailment, including its name, its aetiology, and its treatment (Banks \& Prior, 2001; Lian and Nettleton, 2014). When bodily problems are not identified by biomarkers, nor explained theoretically, they are often interpreted as "manifestations of the mind" (Nettleton et al., 2004: 63), and constructed as psychogenic in origin. In contemporary Western societies, where less physical means less real (Jutel, 2011: 13), the condition thereby "escape the reality principle by apparently existing only in terms of subjective experience" (Cohn, 1999: 195). When patients contest this interpretation, it reflects their desire to seek acceptance for having an actually existing disease and thus permission to be ill (Aronowitz, 1998; Nettleton et al., 2004; Nettleton, 2006).

In their free-text comments, the lack of mutual understanding is mentioned by several women, often in connection with a change of GPs: "I have also replaced GPs because of huge disagreements about the cause of the illness". Several women experienced that their GPs did not think of ME as a disease or a legitimate diagnosis (“Some doctors did not 'believe' the illness"), that they disagreed with ME diagnosis set by other doctors ("my GP does not agree"), or that they did not believe that the patient had a disease ("I needed to understand that it was nothing wrong with me"). Several women stressed that ME "it is as physical as it can be", and that a "psychic interpretation is directly health damaging for ME-sufferers".

There is no reason to believe that members of the Norwegian ME-organisation differ significantly from non-members (or even from people suffering from other medically unexplained and contested conditions) in these matters. All over the Western world, MEpatients contest psychogenic aetiologies of their illness, as well as their treatment implications, in a wide range of public arenas: in virtual communities on the internet (Lian and Nettleton, 2014), in public media (de Wolfe, 2009), and in consultation rooms (Banks \& Prior, 2001). The same debate is also found for other contested conditions, such as 
fibromyalgia and multiple chemical sensitivity: patients often banish the possibility that their illness has a psychogenic origin, and express frustration at doctors who refuse to recognize their symptoms as signs of a "real" disease (Barker, 2008; Dumit, 2006). For these reasons, congruence in patient-doctor views is probably important not only for ME-patients, but also for other patients suffering from medically unexplained and contested conditions.

\section{Last 12 months}

Logistic regression analyses revealed that for all four quality aspects, the patient's experiences were significantly associated with longer duration of their GP relation, and higher number of GP visits. Assessments were likely to be more positive in women whose GP relationship had lasted for 3 years or more compared to those with a shorter relationship (Table 5), and even more so by those who reported more than ten visits compared to those with 1-4 visits last year (Table 5).

We interpret both findings (e.g. duration over time and frequency) as an indication of the importance of "interpersonal continuity" in patient satisfaction. Interpersonal continuity refers to a longitudinal continuity in a personal relationship between patient and doctor that enhance personal trust, empathy, responsibility and mutual knowledge (knowledge not necessarily recorded in formal records, but accumulated through repeated meetings over a period of time) (Saultz \& Albedaiwi, 2004; Haggerty et al., 2003). Positive experiences of past events nurture positive expectations of future events, and thereby interpersonal trust (Guthrie, 2008). Our findings are in line with previous research showing that continuity of care is associated with higher degree of patient satisfaction (Saultz \& Albedaiwi, 2004; Raivio et al., 2014), especially for women with chronic conditions and low self-rated health (Nutting et al., 2003). 
Based on free-text comments from some of the women, this satisfaction is usually not tied to the GPs knowledge about ME, or they ability to help them, but the extent to which they exhibit efforts to try to help: "I am very satisfied with my GP, she knows little about the disease but has shown an exceptional will to learn".

\section{Explanatory factors: which is which?}

In studies of patient satisfaction, underlying theoretical assumptions are not always explicitly formulated or critically addressed, but they are always present. Emphasising individual variables, for instance, means that we perceive patient satisfaction either as a function of patient characteristics (such as low education in patients equals poor health literacy, defined as an individual's ability to seek, understand, and use health information, which again affect their health communication in clinical setting), as a function of the way they are treated by the doctor, or a combination of the two. Individual and relational factors are closely intertwined, but which is which? According to a review article, doctors practice a more directive and less participatory consulting style with patients from lower socioeconomic positions, compared to patients from higher socioeconomic positions (Willems et al., 2005: 143). Does this mean that doctors treat patients differently, according to their socioeconomic position, or that socioeconomic position affects the ways in which patients behave? While trying to understand the complex mechanisms underlying patient satisfaction, such difficult questions can only be discussed - not answered.

\section{Limitations}

Our data is collected from a patient organization, which means that we have not reached nonorganised ME-sufferers. This means that they could describe their experiences without fearing negative consequences for their relation with their GPs, but it could also limit the validity of our data. Because the questionnaire was distributed via email, only half of the members received the invitation (those who had given their email address). If the receiving 
group was biased in terms of age and education, we might have a selection bias that could have influenced our results. This bias does not necessarily exist in a country where $93 \%$ of the households have internet access (Statistics Norway, 2012). We do, however, expect to have a selection bias towards those that are less seriously affected (because they do not have the ability to participate). Other limitations of our study relates to the more general weaknesses of survey data related to patient satisfaction: the respondents might have different standards for acceptable care, and they might define core concepts differently (especially in our case, as our questions entail complicated concepts like respect and trust), and thereby interpret the questions differently. Also, they might not remember things that happened a long time ago (some questions require that they remember what happened several years ago, and the ways in which they interpret these experiences in retrospect might change over the years, as things progress).

\section{Conclusion}

The results of our analyses illuminates the importance of relational factors in facilitating patient satisfaction in relation to several aspects of the medical encounter: patient's sense of partnership and shared decision-making, experience of being taken seriously and being paid due respect, and congruence in the ways in which doctor and patient understand their illness. Whereas the association between patient satisfaction and relational factors were statistically significant, patient's education and health status were not. This was found for both phases and all seven models. Contrary to much previous research, none of the individual factors (education and self-rated health) were statistically significantly associated with patient satisfaction in any of the models, although there was a non-significant tendency that those reporting lower self-rated health were less satisfied. 
In our study of ME patients, relational factors did outweigh the importance of more individual factors, even education and health status, two factors usually found to be important explanatory factors in studies of patient satisfaction. We interpret this finding as related to the condition of the patients we have studied: a medically contested stigmatising low-status diagnosis with disputed aetiologies, gendered connotations, uncertain duration, no reliable biomarkers and no known medical cure. It might be the contested nature of ME that make relational factors so important. 


\section{References}

Anderson VR, Jason LA, Hlavaty LE, Porter N. \& Cudia J. (2012) A review and metasynthesis of qualitative studies on Myalgic Encephalomyelitis/chronic fatigue syndrome. Patient Education and Counseling 86(2): 147-155.

Aronowitz RA (1998) Making sense of illness: Science, society and disease. Cambridge: Cambridte University Press.

Banks J \& Prior L (2001) Doing things with illness. The micro politics of the CFS clinic. Social Science and Medicine 52(1): 11-23.

Barker KK (2008) Electronic support groups, patient-consumers, and medicalization: the case of contested illness. Journal of Health and Social Behavior 49(1): 20-36.

Beach MC, Roter D, Korthuis PT, Epstein RM, SharpV, Ratanawongsa N, Cohn J, Eggly S, Sankar A, \& Moore RD (2013) A multicenter study of physician mindfulness and health care quality. The Annals of Family Medicine 11(5): 421-428.

Beasant L, Mills N, \& Crawley E (2014) Adolescents and mothers value referral to a specialist service for chronic fatigue syndrome or myalgic encephalopathy (CFS/ME). Primary Health Care Research \& Development 15(2): 134-142.

Budych K, Helms TM, \& Schultz C (2012) How do patients with rare diseases experience the medical encounter? Exploring role behavior and its impact on patient-physician interaction. Health Policy 105(2): 154-164.

Capelli E, Zola R, Lorusso L, Venturini L, Sardi F \& Ricevuti G (2010) Chronic fatigue syndrome/myalgic encephalomyelitis: an update. International Journal of Immunopathology and Pharmacology 23(4): 981-989. 
Carruthers BM, van de Sande MI, De Meirleir KL, Klimas NG, Broderick G, Mitchell T, Staines D, Powles AC, Speight N, Vallings R, Bateman L, Baumgarten-Austrheim B, Bell DS, Carlo-Stella N, Chia J, Darragh A, Jo D, Lewis D, Light AR, MarshallGradisbik S, Mena I, Mikovits JA, Miwa K, Murovska M, Pall ML \& Stevens S (2011) Myalgic encephalomyelitis: International Consensus Criteria. Journal of Internal Medicine 270(4): 327-338.

Chew-Graham C, Dowrick C, Wearden A, Richardson V \& Peters S (2010) Making the diagnosis of Chronic Fatigue Syndrome/Myalgic Encephalitis in primary care: a qualitative study. BMC Family Practice 11(1): 16. doi:10.1186/1471-2296-11-16.

Cohn S (1999) Taking time to smell the roses: Accounts of people with chronic fatigue syndrome and their struggle for legitimisation. Anthropology \& Medicine 6(2): 195215.

Croker JE, Swancutt DR, Roberts MJ, Abel GA, Roland M \& Campbell JL (2013) Factors affecting patients' trust and confidence in GPs: evidence from the English national GP patient survey. BMJ open 3(5).

de Wolfe,P. (2009) ME: The rise and fall of media sensation. Medical sociology online 4(1): $2-13$.

Dumit J (2006) Illnesses you have to fight to get: Facts as forces in uncertain, emergent illnesses. Social Science \& Medicine 62(3): 577-590.

Edwards CR, Thompson AR \& Blair A (2007) An 'overwhelming illness'. Women's experiences of learning to live with chronic fatigue syndrome/myalgic encephalomyelitis. Journal of Health Psychology 12(2): 203-214. 
Epstein RM, Shields CG, Meldrum SC, Fiscella K, Carroll J, Carney PA \& Duberstein PR (2006) Physicians' responses to patients' medically unexplained symptoms. Psychosomatic Medicine 68(2): 269-276.

Fluge Ø, Bruland O, Risa K, Storstein A, Kristoffersen EK, Sapkota D, Næss H, Dahl O, Nyland H \& Mella O (2011) Benefit from B-Lymphocyte depletion using the antiCD20 antibody Rituximab in chronic fatigue syndrome. A double-blind and placebocontrolled study. PLoS ONE 6, e26358.

Guthrie BS (2008) Continuity of care matters. BMJ 337: a867.

Haggerty JL, Reid RJ, Freeman GK, Starfield BH, Adair CE \& McKendry R (2003) Continuity of care: a multidisciplinary review. BMJ 327(7425): 1219-1221.

Hall JA \& Dornan MC (1990) Patient sociodemographic characteristics as predictors of satisfaction with medical care: A meta-analysis. Social Science \& Medicine 30(7): 811-18.

Hall JA, Gulbrandsen P \& Dahl FA (2014) Physician gender, physician patient-centered behavior, and patient satisfaction: A study in three practice settings within a hospital. Patient Education and Counseling 95(3): 313-318.

Hall JA \& Roter DL (2002) Do patients talk differently to male and female physicians? A meta-analytic review. Patient Education and Counseling 48(3): 217-224.

Hansen AH, Kristoffersen AE, Lian OS, and Halvorsen PA (2014) Continuity of GP care is associated with lower use of complementary and alternative medical providers: a population-based cross-sectional survey. BMC health services research 14, 629 .

Hart B \& Grace VM (2000) Fatigue in chronic fatigue syndrome: a discourse analysis of women's experiential narratives. Health Care Women International 21(3): 187-201. 
Hibbard JH \& Greene J (2013) What the evidence shows about patient activation: better health outcomes and care experiences; fewer data on costs. Health Affairs 32(2): 207214.

Horton-Salway M (2002) Bio-psycho-social reasoning in GPs' case narratives: the discursive construction of ME patients' identities. Health: An Interdisciplinary Journal for the Social Study of Health, Illness and Medicine 6, (4) 401-421.

Jackson JL, Chamberlin J \& Kroenke K (2001) Predictors of patient satisfaction. Social Science \& Medicine 52(4): 609-620.

Jewson ND (2009) The disappearance of the sick-man from medical cosmology, 1770-1870. International Journal of Epidemiology 38(3): 622-633.

Jutel AG (2011) Putting a name to it. Diagnosis in contemporary society. Baltimore: The John Hopkins University Press.

Krupat E, Bell RA, Kravitz RL, Thom D \& Azari R (2001) When physicians and patients think alike: patient-centered beliefs and their impact on satisfaction and trust. Journal of Family Practice 50(12): 1057-1062.

Lian OS and Bondevik H (2015) Medical constructions of long-term exhaustion - past and present. Sociology of Health \& Illness 37(6) (in press).

Lian OS and Nettleton S (2014) "United we stand": Framing myalgic encephalomyelitis in a virtual symbolic community. Qualitative Health Research doi:10.1177/1049732314562893.

Moss P \& Dyck I (2002) Women, body, illness: Space and identity in the everyday lives of women with chronic illness. Lanham: Rowman \& Littlefield Publishers. 
Nettleton S (2006) 'I just want permission to be ill': towards a sociology of medically unexplained symptoms. Social Science \& Medicine 62(5): 1167-1178.

Nettleton S, O'Malley L, Watt I \& Duffey P (2004) Enigmatic illness: Narratives of patients who live with medically unexplained symptoms. Social Theory \& Health 2(1): 47-66.

NICE (2014) Chronic fatigue syndrome/myalgic encephalomyelitis (or encephalopathy): Diagnosis and management of CFS/ME in adolescents and children. Available at: http://publications.nice.org.uk/chronic-fatigue-syndromemyalgic-encephalomyelitisor-encephalopathy-cg53 (accessed 20 January 2015).

Nutting PA, Goodwin MA, Flocke SA, Zyzanski SJ, \& Stange KC (2003) Continuity of primary care: to whom does it matter and when? The Annals of Family Medicine 1(3): 149-155.

olde Hartman, TC (2011) Persistent medically unexplained symptoms in primary care. The patient, the doctor and the consultation.Nijmegen: Radboud University Nijmegen Medical Centre.

olde Hartman TC, van Rijswijk E, van Dulmen S, van Weel-Baumgarten E, Lucassen PL \& van Weel C (2013) How patients and family physicians communicate about persistent medically unexplained symptoms. A qualitative study of video-recorded consultations. Patient Education and Counseling 90(3): 354-360.

Ommen O, Thuem S, Pfaff H \& Janssen C (2011) The relationship between social support, shared decision-making and patient's trust in doctors: a cross-sectional survey of 2,197 inpatients using the Cologne Patient Questionnaire. International Journal of Public Health 56(3): 319-327. 
Rahmqvist,M. \& Bara,A.C. (2010) Patient characteristics and quality dimensions related to patient satisfaction. International Journal for Quality in Health Care DOI: http://dx.doi.org/10.1093/intqhc/mzq008.

Raivio R, Holmberg-Marttila D \& Mattila KJ (2014) Patients' assessments of the continuity of primary care in Finland: a 15-year follow-up questionnaire survey. British Journal of General Practice 64(627): e657-e663.

Sacristán JA (2013) Patient-centered medicine and patient-oriented research: omproving health outcomes for individual patients. BMC Medical Informatics \& Decision Making 13(6): 1-8.

Salmon P, Ring A, Dowrick CF \& Humphris GM (2005) What do general practice patients want when they present medically unexplained symptoms, and why do their doctors feel pressurized? Journal of Psychosomatic Research 59(4): 255-260.

Sans-Corrales M, Pujol-Ribera E, Gene-Badia J, Pasarín-Rua MI, Iglesias-Pérez B \& Casajuana-Brunet J (2006) Family medicine attributes related to satisfaction, health and costs. Family Practice 23(3): 308-316.

Saultz JW \& Albedaiwi W (2004) Interpersonal continuity of care and patient satisfaction: a critical review. The Annals of Family Medicine 2(5): 445-451.

Schieber AC, Kelly-Irving M, Delpierre C, Lepage B, Bensafi A, Afrite A, Pascal J, Cases C, Lombrail P \& Lang T (2013) Is perceived social distance between the patient and the general practitioner related to their disagreement on patient's health status? Patient Education and Counseling 91(1): 97-104.

Serber ER, Cronan TA \& Walen HR (2003) Predictors of patient satisfaction and health care costs for patients with fibromyalgia. Psychology \& Health 18(6): 771-787. 
Shirley ED \& Sanders JO (2013) Patient Satisfaction: Implications and Predictors of Success. The Journal of Bone \& Joint Surgery 95(10): e69-4.

Statistics Norway (2012) Bruk av IKT i husholdningene, 2012, 2. kvartal [Use of ICT in households, 2012, $2^{\text {nd }}$ quarter]. Available at: http://ssb.no/ikthus (accessed 20 January 2015).

Statistics Norway (2014a) Helseforhold, levekårsundersøkelsen, 2012 [Health, care and social relations, survey on living conditions, 2012]. Available at: http://www.ssb.no/helseforhold (accessed 20 January 2015).

Statistics Norway (2014b) Population's level of education, 1 October 2013. Available at: http://www.ssb.no/en/utdanning/statistikker/utniv/aar/2014-06-19 (accessed 20 January 2015).

Stone L (2014) Managing the consultation with patients with medically unexplained symptoms: a grounded theory study of supervisors and registrars in general practice. BMC Family Practice 15(1): 192.

Street RL, Gordon HS, Ward MM, Krupat E \& Kravitz RL (2005) Patient participation in medical consultations: why some patients are more involved than others. Medical Care 43(10): 960-969.

Swoboda DA (2008) Negotiating the diagnostic uncertainty of contested illnesses: physician practices and paradigms. Health: An Interdisciplinary Journal for the Social Study of Health, Illness and Medicine 12(4): 453-478.

Thom DH (2001) Physician behaviors that predict patient trust. Journal of Family Practice 50(4): 323-328.

Thompson R, Isaac CL, Rowse G, Tooth CL \& Reuber M (2009) What is it like to receive a diagnosis of nonepileptic seizures? Epilepsy \& Behavior 14(3): 508-515. 
Toombs SK (1992) The meaning of illness. A phenomenological account of the different perspectives of physician and patient. Dordrecht: Kluwer Academic Publishers.

Weisman CS \& Teitelbaum MA (1985) Physician gender and the physician-patient relationship: recent evidence and relevant questions. Social Science \& Medicine 20(11): 1119-1127.

Werner A, Isaksen LW \& Malterud K (2004) 'I am not the kind of woman who complains of everything': Illness stories on self and shame in women with chronic pain. Social Science \& Medicine 59(5): 1035-1045.

Werner A \& Malterud K (2003) It is hard work behaving as a credible patient: encounters between women with chronic pain and their doctors. Social Science \& Medicine 57(8): 1409-1419.

Whear R, Abdul-Rahman AK, Thompson-Coon J, Boddy K, Perry MG \& Stein K (2013) Patient initiated clinics for patients with chronic or recurrent conditions managed in secondary care: a systematic review of patient reported outcomes and patient and clinician satisfaction. BMC Health Services Research 13(1): 501.

Willems S, De Maesschalck S, Deveugele M, Derese A \& De Maeseneer J (2005) Socioeconomic status of the patient and doctor-patient communication: does it make a difference? Patient Education and Counseling 56(10): 139-146.

Wyller VB, Eriksen HR \& Malterud K (2009) Can sustained arousal explain the Chronic Fatigue Syndrome? Behavioral and Brain Functions 5(10): 1410-1420.

Åsbring P \& Narvanen AL (2002) Women's experiences of stigma in relation to chronic fatigue syndrome and fibromyalgia. Qualitative Health Researh 12(2): 148-160. 


\section{Endnotes}

${ }^{1}$ All inhabitants are allocated to a named GP (if they so wish), of their own choice, and they are allowed to change GPs twice a year. About 99,6 percent of the population is enrolled in this system (Hansen et al, 2014).

\section{Tables (see separate document)}

Table 1. Sample characteristics

Table 2. Assessment of initial GP contacts

Table 3. Assessment of current GP

Table 4. Female ME patients' assessment of the initial contact with the general practitioner (age adjusted multivariable logistic regressions)

Table 5. Female ME patients' assessment of contacts with their current general practitioner (age adjusted multivariable logistic regressions) 